\title{
FARIA E SOUSA, A FORTUNA E O DISCURSO INCRIMINATÓRIO'
}

\author{
FARIA E SOUSA, THE FORTUNA \\ AND THE INCRIMINATORY SPEECH
}

Mauricio Massahiro Nishihata²

RESUMO: Na década de 1640, Manuel de Faria e Sousa (1590-1649) compôs a sua Fortuna (...), relato de vida em que o escritor narra em primeira pessoa a sua corrente de trabalhos, estribado na condição de secretário de notáveis senhores da corte de Filipe IV. Nela, o letrado português apronta uma defesa de conduta que, ao mesmo tempo, desata numa contundente acusação contra Manuel de Moura Corte Real, embaixador de Espanha em Roma, a quem o escritor atribui a autoria de uma série de delitos e torpezas contra o bem comum. $O$ presente texto visa a estudar parte dos recursos retóricos aplicados no papel seiscentista, na exposição dos supostos crimes cometidos pelo aristocrata luso-espanhol.

PALAVRAS-CHAVE: Literatura Portuguesa. Retórica. União Ibérica. Século 17. Crimes.

\begin{abstract}
In the 1640's, Manuel de Faria e Sousa (1590-1649) composed his Fortuna (...), a life story in which the writer narrates in first person his current of works, supported as secretary to notable gentlemen from the court of Philip IV. In it, the Portuguese scholar prepares a defense of conduct that, at the same time, unleashes a scathing accusation against Manuel de Moura Corte Real, ambassador of Spain in Rome, to whom the writer attributes the authorship of a series of crimes and turpitudes against the good common. This text aims to study part of the rhetorical resources applied to the 17th century paper, in the exposition of the alleged crimes committed by the Portuguese-Spanish aristocrat.
\end{abstract}

KEYWORD: Portuguese Literature. Rhetoric. Iberian Union. 17th Century. Crimes.

\footnotetext{
${ }^{1}$ Artigo recebido em 30 de agosto de 2021 e aceito para publicação em 20 de outubro de 2021.

2 Doutor em Letras pela Universidade de São Paulo; Integrante do grupo Poligrafaria: La polygraphie dans l'aire ibérique: écrits et figure de Manuel de Faria e Sousa (1590-1649). E-mail: mauricio. nishihata@alumni.usp.br. ORCID: https://orcid.org/0000-0001-8370-4246. Este texto é um desdobramento de uma exposição oral apresentada no II SILC, no simpósio "Articulações entre doenças, crimes e textos literários", transcorrido em 11 de agosto de 2021.
} 


\section{Faria e Sousa}

Manuel de Faria e Sousa (1590-1649) é amplamente conhecido pela produção de um alargado rol de títulos. O Nobiliario (1646), último impresso em vida do escritor, apresenta um catálogo de seus papéis, contemplando cerca de 50 tomos de variados gêneros discursivos. O polígrafo notabilizou-se pela composição da série de livros históricos a propósito das Conquistas do Império ultramarino (Ásia Portuguesa, 3 tomos, 1666-75; Europa Portuguesa, 3 tomos, 1667-80 e África Portuguesa, 1681), bem como pelos chamados comentários à poesia camoniana. Já desde o final do século XVI, os leitores de Camões invocavam o surgimento de um texto de apoio, que viesse a aclarar os lances poéticos da epopeia camoniana, já naquele tempo percebida como contendo um punhado de mistérios no tratamento das fábulas mitológicas, bem como das alusões históricas. Eugenio Asensio bem observou que somente os leitores mais doutos conseguiam fazer um bom aproveitamento da erudita epopeia camoniana (ASENSIO, 1980, p. 112). Faria e Sousa enfileirou-se à categoria dos comentadores de Camões ao publicar os Lusíadas comentados (1639) que, na tipografia de Ivan Sanchez, foram impressos em papéis vulgares e de luxo. A obra, tendo levado cerca de 25 anos para ficar pronta, oferece enormes contributos à camonologia. Faria e Sousa desenvolveu os chamados elementos de comentários, em que evidenciou a rede de imitação (imitatio) que ia descobrindo para cada elemento do poema. Jorge de Sena considerou os Lusíadas comentados como "um dos mais extraordinários monumentos erguidos por alguém, devotamente, a um poeta e a uma cultura" (SENA, 1972, p. 9). As Rimas varias (5 tomos, 1685-89) vieram à luz em Portugal, postumamente, já sob um outro contexto sócio-político.

Manuel de Faria e Sousa passou a maior parte de sua vida ativa na Espanha, onde atuou como secretário de importantes aristocratas a serviço de Filipe IV. Com particularidade, o escritor português presenciou o momento da dissolução da União Ibérica, quando, em 1640, o reino de Portugal retomou a sua independência política, com a subida da dinastia Bragança ao poder. Sob a designação de um autor "hispanizado", o letrado português jogou conforme as regras do mecenato. Faria e Sousa compôs diversas obras de encomendas, surgidas em razão de uma circunstância 
digna de memória. Assim, eventos como o nascimento de um pequeno infante, a celebração das bodas reais, a morte prematura de um herdeiro, etc, receberam a atenção da pena do autor. Faria e Sousa redigiu a maior parte de seus escritos na língua espanhola. Entre outros letrados atuantes no Portugal Habsburgo, destacam-se Heitor Pinto (1528-1584), autor da Imagem da vida cristã (1563, I parte), e Francisco Manuel de Mello (1608-1666). Tal como Faria e Sousa, o célebre autor do Hospital das letras (1657) exerceu ofícios palatinos em diversos destinos na Europa.

\section{A Fortuna}

A Fortuna de Manuel de Faría consiste na assim chamada autobiografia do autor seiscentista. Sob o molde predominante de uma vida particular, nela o escritor narra as quadras de sua vida. Ele rememora a infância transcorrida no Norte de Portugal, a história ilustre de seus antepassados, entre outros temas afins ao gênero. A tópica educação (educatio) adquire grande relevo na obra. A criança recebia instruções dos mestres de aldeia, que Ihe inculcavam os rudimentos dos studia humanitatis. $\mathrm{O}$ texto de memória inclui a partida do letrado para a Espanha, na busca por fazer-se na vida. O bom domínio da leitura e escrita poderia render-Ihe empregos de escrevente, na aparatosa burocracia da corte espanhola. Por vezes os tempos da narração e da enunciação discursiva imbricam-se na obra, ocasião oportuna para o escritor exarar as agruras que vinha sofrendo de uma velhice tão pouco remediada, frustrado com a ingratidão dos homens, que teriam se recusado a conferir o devido valor de suas façanhas literárias, conforme dedicou diversas obras de ilustração à pátria.

De datação incerta, a Fortuna foi redigida ao longo da década de 1640. Aos cuidados do estudioso Edward Glaser (19181972), o título foi publicado pela primeira vez em 1975, tendo sobrevivido através de dois manuscritos apógrafos, ambos datados do final do século XVII ou início do XVIII: a "Fortuna de Manuel de Faria e Sousa", depositada no Arquivo Distrital de Braga; e a "Fortuna, y vida de Manoel de Faria e Souza cavallero de la Orden del Cristo de la Casa Real. Libro V", em depósito na Biblioteca da Universidade de Michigan. 
A Fortuna amplifica a matéria das ocupações (empleos) e da fortuna do letrado, centrando-se no relatório de serviços a três importantes senhores. Na juventude, Faria e Sousa desempenhou a função de acólito do frei Gonçalo de Morais, servindo-o como amanuense. O jovem, muito empenhado, enfurnava-se no escritório do padre, desde o amanhecer até horas avançadas da noite. $\mathrm{O}$ bispo do Porto guardava intenções de reservar a carreira eclesiástica ao jovem. No entanto, Faria e Sousa inclinava-se à vida civil, propensão que se confirma com o seu casamento com dona Catarina Machado, que concebe dez filhos (destes, apenas três vingam). Os serviços ao bispo desandam, chegando ao fim com o enlace matrimonial do escritor. Já na Espanha, Faria e Sousa atua como secretário de Pedro Álvares Pereira. Sob a proteção deste importante herdeiro dos Álvares Pereira, Faria e Sousa teria encontrado uma melhor sina, caso a sorte lhe tivesse sido favorável. No entanto, o imponente membro do Conselho de Portugal morre em 1622, o que lhe impede de ter uma grande virada na carreira. E, finalmente, o escritor serve o nobre espanhol Manuel de Moura y Corte Real (1592-1651), mais conhecido pelo título de II marquês de Castelo Rodrigo, ou simplesmente marquês de Castelo Rodrigo.

Como se sabe, o marquês de Castelo Rodrigo pertencia ao poderoso clã da "família de Moura" (FARIA E SOUSA, 1975, p. 182), que adquire grande destaque durante a crise sucessória. Com o desaparecimento do rei Sebastião (1554-1578?) na batalha contra os árabes em Alcácer-Quibir, e sucedida a morte do cardeal Henrique I (1512-1580), que ocupa o trono num breve governo tampão, Portugal não tinha um herdeiro direto para a continuação da linhagem real. Diversos candidatos reivindicaram a sucessão do trono, entre eles, Antonio de Portugal, prior do Crato, disposto a resistir contra o assédio espanhol. Nessa agitada contenda, o nobre lusitano Cristóvão de Moura e Távora (1538-1613) advogou em prol da causa filipina. Em 1581, as Cortes de Tomar deliberaram as condições sob as quais Portugal rendia-se ao domínio da Espanha. A junta assegurou um conjunto de medidas favoráveis ao reino de Portugal, como a criação do Conselho de Estado. Assim, sob uma nova acomodação dos atores políticos, os membros da família de Moura, que haviam se mostrado favoráveis ao projeto da união das Duas Coroas, beneficiaram-se com a ascensão de Filipe II ao poder de Portugal, onde o soberano atendia pelo 
título de Filipe I. Cristóvão de Moura e Távora foi alçado à posição de vice-rei de Portugal, tendo sido elevado a I marquês de Castelo Rodrigo. Em respectivo, igualmente o II marquês de Castelo Rodrigo assumiu importantes postos no governo filipino. Ele disputou com Gaspar de Guzmán y Pimentel (1587-1645), conde-duque de Olivares, a condição de principal ministro de Filipe IV. Em 1621, ao ser entronado aos 16 anos de idade, o jovem rei confiou a função de despacho ao nobre de origem italiana, praticamente se tornando o braço absoluto do reino espanhol. As más línguas diziam que o conselheiro principal era adepto das práticas de feitiçaria, havendo captado a mente do rei. As rivalidades palacianas entre Castelo Rodrigo e o conde-duque de Olivares explicam as razões por que o primeiro foi escalado para atuar à distância da corte, liderando missões em Portugal, Roma e Alemanha, onde veio a falecer. Em suma, é aceite que os Moura-Corte Real passaram de uma família de médio estatuto para alto poder aristocrático ${ }^{3}$. 0 marquês de Castelo Rodrigo foi conhecido como um habilidoso político, com refinado gosto pelas artes.

O centro do discurso da Fortuna localiza-se na narração dos acontecimentos ocorridos sob o mando de Castelo Rodrigo. Em seu discurso de vida, o escritor reflete sobre as atividades de secretaria ao nobre Castelo Rodrigo, a quem se ligou por volta de 1626. Em especial, o autor medita o período compreendido entre os anos de 1632 e 1634 . Por volta de 1631, Filipe IV nomeia Castelo Rodrigo como embaixador extraordinário de Espanha em Roma, escalado para atuar no cargo de representação na corte do papa Urbano VIII. Faria e Sousa integra a jornada formada por mais de cem funcionários a serviço de Castelo Rodrigo, que parte de Madrid a Roma 4 .

$\mathrm{Na}$ Cidade Eterna, Faria e Sousa desentende-se frontalmente com o aristocrata, razão que o faz abandonar a legação romana em plena atividade. Ao tornar a Madrid, o letrado deposita graves denúncias contra Castelo Rodrigo. O conde-duque de Olivares ouve com atenção as queixas do letrado, decidindo-se por instaurar uma comissão de egrégios para averiguar os procedimentos de Castelo Rodrigo. Os relatórios decorrentes do proces-

\footnotetext{
${ }^{3}$ MARTíNEZ HERNÁNDEZ, 2009, p. 3.

${ }^{4}$ GARCÍA CUETO, 2007, p. 698.
} 
so de investigação sobre a conduta de Castelo Rodrigo reúnem-se nas "Consultas", depositadas no Archivo Historico Nacional, localizado na capital espanhola 5 .

Na Fortuna, Faria e Sousa examina, com prioridade, os anos transcorridos em Roma, colocando-se a responder a murmuração dos homens que, ainda na década de 1640, possivelmente lhe atribuíam a pecha de ingrato, condenando-o por abandonar abruptamente a casa senhorial dos Moura-Corte Real, em plena atividade na legação romana. A seguir, passemos a examinar o teor ou o conteúdo das acusações que o escritor levanta contra o antigo amo.

\section{0 discurso incriminatório}

Talvez o termo que melhor defina o papel de Faria e Sousa seja o termo infortúnio. A Fortuna narra a história dos insucessos do escritor sob os auspícios de Castelo Rodrigo, a quem o narrador atribui as causas de sua miséria doméstica. Como revelado pelo escritor em diversos papéis de sua pluma, o influente nobre teria impedido o seu crescimento na corte. De modo deliberado, Castelo Rodrigo teria se aproveitado de sua grande influência na corte para desencorajar outros notáveis a nomearem o funcionário para cargos mais expressivos. Diversas vezes o mísero serviçal revelou que o seu ex-amo o submetia a uma condição de vil dependência. Pouco a pouco, Castelo Rodrigo afastou o letrado do cargo de escrevente. Ao sub-aproveitar as suas potencialidades do intelecto, o senhor impediu que o empregado cuidasse das correspondências e arquivo do palácio, atribuindo-lhe atividades muito aquém de suas capacidades, para dor e tortura de um homem douto e laborioso.

A representação da imagem de Castelo Rodrigo tratou-o como um nobre advindo de uma ilustre genealogia, tendo sido educado pelos melhores preceptores do reino. Na Fortuna, contudo, a imagem dourada de um aristocrata acostumado à companhia gentil de príncipes cede lugar a uma composição de um vilão cheio de disfarces. Numa das primeiras páginas da obra, conta-se

${ }^{5}$ Para um brilhante estudo sobre a comissão instaurada por Olivares para averiguar a conduta do embaixador Castelo Rodrigo em Roma, conferir os artigos de MARTíNEZ HERNÁNDEZ. 
que o algoz teria quebrado a fé de um juramento selado entre ambos. Valendo-se de palavras sem lastro, o poderoso nobre teria assegurado ao letrado o seu crescimento na corte de Madrid. Para Faria e Sousa, essas palavras sedutoras haviam sido ditas com o propósito de mantê-lo na casa senhorial, vinculando-o sob as amarras de uma falsa promessa. Assim, a cilada do destino acabou por eliminar-lhe as suas chances de um bom sucesso. Faria e Sousa não atinge um lugar institucional que lhe aprouvesse alguma estabilidade financeira (se assim pudermos nos expressar). Ao desperdiçar um precioso tempo de vida nessa casa senhorial (cerca de doze anos contínuos), o letrado deparou-se com uma má situação nos seus anos finais de vida, vivendo sob o acolhimento caritativo de um parente em Madrid.

Na Fortuna, Castelo Rodrigo é figurado como um homem de caráter baixo. Na composição desse texto de memória, Faria e Sousa reconhece que as suas imprecações contra Castelo Rodrigo veiculavam um teor bastante ímpar. Em outras palavras, o letrado admitia que as revelações inusitadas que havia de fazer sobre Castelo Rodrigo eram tantas, e tão absurdas, que bem poderiam parecer uma mera ilusão (isto é, uma mentira), ao menos para a impressão do discurso comum (dóxa).

Sob a justificativa do bem comum, Faria e Sousa vinha a revelar uma dita verdadeira face de Castelo Rodrigo aos seus auditores ibéricos que, é possível presumir, ignoravam a conduta do embaixador nos bastidores da distante Roma.

Um outro argumento complementar consiste na necessidade de que letrado viesse a defender-se das murmurações dos homens, que ainda na Madrid da década de 1640 estariam a fazer mau juízo do letrado. Assim, a escrita do discurso opera como uma espécie de antídoto para neutralizar o veneno dos homens.

A retórica judiciária classifica os discursos de acordo com os gênero de causa (genera causarum). Nessa categorização, a Fortuna alinha-se ao discurso de causa dúbia (genus dubium ou anceps), em que a opinião do orador encontra-se em choque com a opinião geral.

Com o fito de defender a condição de verdade de seu discurso, Faria e Sousa aplica diversas estratégias para tornar a sua palavra mais convincente. Entre outras, o letrado utiliza o recurso das sementes de provas (semina probationum) como parte de 
um procedimento incriminatório contra Castelo Rodrigo. Como supracitado, um confronto direto contra a parte adversária não seria producente, sobretudo no início do discurso, sob o risco de, logo de imediato, indispor os ouvintes contra a pessoa do orador. No lugar de um tiro direto, cuja probabilidade de acerto era muito reduzida, as sementes de provas operavam como pequenas armadilhas. Com sutileza, a aplicação delas visava a instalar, ainda que minimamente, o estado de dúvidas nos ouvintes.

As certezas do mundo sobre as coisas podiam vacilar, sobretudo se perante um discurso poderoso. Assim, as sementes de provas preparavam os ouvintes antes da exposição em definitivo das provas argumentativas contra o adversário. Como semina probationum, o letrado dissemina fórmulas amplamente conhecidas no exórdio da obra. Entre outras, aplica o conhecido tema do desconcerto do mundo. De remota origem, esse lugar opera a censura dos tempos atuais em comparação com um passado supostamente mais viçoso. Outra imagem recorrente consiste no aproveitamento do tema conhecido como nobreza da alma, lugar constante, por exemplo, entre os filósofos do estoicismo. Sêneca considerava que a honra emanava das ações do homem e menos do sangue dele. Ambos os lugares comuns, veladamente semeados no discurso, adquirem significado após a colocação em definitivo das provas contra o marquês. Nessa produção de sentidos ao nível dos ouvintes, o orador espezinha o lugar aristocrático de Castelo Rodrigo. Se o costume confundia a pureza de sangue com a honra, os tempos coevos eram outros. Nessa lógica, o rico herdeiro é representado como um indivíduo melancólico que, sem o domínio de si, sujeitava-se às intempéries de um humor marcado pela inconstância. Se nos tempos antigos os homens marcavam-se pelo talento na espada e pena, o anti-exemplo apresentado gastava o ócio com frivolidades, tais como jogos e conversas inúteis.

Preparado o terreno para um massacre verbal, o discurso de Faria e Sousa amolda um ataque veemente contra Castelo Rodrigo, a quem se conecta a agência de uma vasta lista de crimes graves. Entre outras diversas faltas, o letrado inculpa o marquês de cometer crimes contra a fazenda, solicitar a falsificação de um registro real e revelar o segredo das cifras. 


\section{Crimes da fazenda}

Na supracitada Consulta do Conselho de Estado, Faria e Sousa acusa Castelo Rodrigo da prática de entesouramento indevido. Entre outros documentos primários disponíveis na pasta, as "Memorias mias para advertir" (Madrid, 13-10-1634), da pluma do letrado, ganham destaque. Nesse papel, o escritor esmiúça os crimes e comportamentos vexatórios de Castelo Rodrigo em 71 $\S \S$. No $1^{\circ} \S$, Faria e Sousa revela o juízo particular do ex-amo para com os assuntos da fazenda. Nos incisos $53^{\circ}, 54^{\circ}$ e $55^{\circ}$, o letrado traz mais especificações sobre como Castelo Rodrigo usava a máquina do Estado espanhol em benefício particular. Na Fortuna, Faria e Sousa afirma que os Moura-Corte Real instituem uma facção criminosa. A partir da prática do nepotismo, Castelo Rodrigo teria distribuído, de modo desenfreado, altos cargos e emolumentos ao círculo de familiares e amigos íntimos. ${ }^{6} \mathrm{Na}$ composição de um perfil horrendo de Castelo Rodrigo, em algumas partes Faria e Sousa atribui-Ihe as propriedades de um polvo. Na fisiognomonia, é comum associar o polvo à traição.

\section{Falsificaçăo de papéis}

Na lliada, Ulisses falsifica uma carta em nome de Príamo. No texto ficto, o rei de Tróia afirmava que estava muito agradecido pela ajuda recebida de Palamedes numa missão e, como forma de recompensa, enviava uma determinada quantia em dinheiro. $\mathrm{Na}$ continuação desse plano, o rei de Ítaca suborna um escravo de Palamedes, que planta a exata soma de moedas, conforme relatada na carta, entre os pertences de Palamedes. Instalada a tramoia, o habilidoso aqueu faz cair as suspeitas contra o príncipe da Eubéia. Os gregos encontram a carta falso Príamo na tenda da vítima, bem como o valor em moedas que o escravo corruptível havia plantado a mando do astucioso aqueu. A vingança de Ulisses causa a desgraça de Palamedes, que é sentenciado a uma morte imerecida.

\footnotetext{
6 “atendiendo sólo a su particular, no había duda en que era muy fácil, pero muy difícil si se había de hacer atendiendo al servicio del rey. Así como yo no podía contenerme para disimular lo que entendía, él menos para dejar de decir al marqués lo que me escuchaba; pareciéndole mal, porque por los medios que el marqués quería enriquecer a sus hijos, quería él que el suyo enriqueciese" (FARIA E SOUSA, 1975, p. 296).
} 
$\mathrm{Na}$ Madrid dos Áustrias, diversos falsários adquiriram enorme fama. Um dos mais famosos foi Miguel de Molina, funcionário do conde de Saldanha, que falsificou mais de 300 papéis, entre acordos, cartas, decretos, cédulas e ordens. A surpreendente história desse escritor suspeitíssimo foi colhida por Ivan de Quiñones, no Tratado de falsedades (...), (1642). O intuito do falsário era obter vantagens financeiras a partir da prática sistemática de adulteração de documentos. A habilidade do mentiroso na imitação da assinatura dos dignatários era tamanha, que conseguia enganar até mesmo os maiores peritos da técnica caligráfica. Como pena, as Partidas previam a mutilação da mão do falso escrevente. ${ }^{7}$ Contudo, dada a benevolência de Filipe IV, em 1641 o delinquente sofreu somente a condenação pela forca, cujo corpo foi queimado em praça pública após a sua morte ${ }^{8}$.

Na Fortuna, Faria e Sousa revela um plano ganancioso de Castelo Rodrigo, que o teria intimado a adulterar um registro real. O letrado mostra-se desconfortável com a indecência do pedido, ao passo que o nobre desconversa, garantindo que a pequena contravenção não passava de um detalhe sem importância. Castelo Rodrigo insiste, assinalando as passagens do ofício que deviam ser alteradas por outros termos no processo de contrafação. Faria e Sousa abre uma longa reflexão acerca dessa má aventura. Ele indaga se o delito poderia ser, na verdade, uma cilada, com o fim de comprometê-lo com a justiça. Se a falsificação fosse descoberta, o escândalo poderia encerrar a sua carreira de letrado, tendo em vista que a profissão das letras requeria credibilidade para o exercício de suas funções. Ao mesmo tempo, o escritor medita se uma eventual recusa poderia lhe trazer chateações ainda maiores. No fim das contas, o letrado decide não sujar as mãos com esse serviço, respondendo que nada o obrigava a cumprir este tipo de ordem. A recusa endossa ainda mais a insatisfação do aristocrata para com o funcionário, que sofre diversas violências verbais ao longo dos doze anos de serviços ${ }^{9}$.

\footnotetext{
${ }^{7}$ EXTREMERA EXTREMERA, 2005, p. 470.

${ }^{8}$ MARAÑÓN, [19--], p. 78-9.

9 “Llamóme el marqués un día y no me dijo menos de que le era necesario que yo falsificase una carta y firma del rey. Esto era a la entrada de la negociación de unos millones que el rey pretendía le concediese el papa en los eclesiásticos. Díjome estas palabras: Yo tengo aquella carta del rey que es fuerza mostrar al agente de Portugal, Miguel Suárez, mas porque hay en ella cosas que deseo no vea, quisiera que me diciéredes otra, imitando bien las letras del secretario y del rey para que no se dude de que es la propia; y esto ha de ser después que yo añadiere y quitare lo que fuere necesario." (FARIA E SOUSA, 1975, p. 294).
} 


\section{Revelaçầo das instruçôes reais}

Em De conscribendis epistolis (1536), Juan Luis Vives aborda a questão do segredo de Estado. O escritor valenciano recorda que, nos tempos da latinidade, o uso da língua grega fazia-se presente para velar o conteúdo de determinadas mensagens. No entanto, com o crescente interesse pela língua estrangeira, esse recurso de comunicação tornou-se improcedente, pelo desvendamento das mensagens que se pretendiam ocultas. Em substituição dessa prática, as secretarias convencionaram o uso de cifras ou notas herméticas. $\mathrm{O}$ conhecimento dos códigos era restrito para poucos, para garantir a manutenção dos segredos. ${ }^{10}$ Faria e Sousa afirmou que, nos serviços de embaixada, um oficial era encarregado de manipular as correspondências cifradas com exclusividade, versado na arte da diagrafia. ${ }^{11}$ Os códigos das embaixadas instruíam que o secretário trancasse o escritório com chaves, para cada vez que deixasse o aposento ${ }^{12}$.

Na Fortuna, Faria e Sousa acusa Castelo Rodrigo de revelar as instruções de governo a um de seus funcionários diletos. As referidas instruções consistiam no propósito da missão, isto é, o objetivo que cada missão diplomática devia atingir ao fim do período de embaixada. Michel de Montaigne, ao refletir sobre o modo de proceder dos embaixadores, bem observou que os ministros "têm maior latitude, e em certos pontos podem agir livremente, pois sua missão não é simplesmente executar e sim esclarecer e orientar com seus conselhos a opinião de quem representam" (MONTAIGNE, 2016, p. 112). Visto isto, Faria e Sousa censurou Castelo Rodrigo, ao quebrar a confiança que o rei lhe havia depositado. Além disso, a ação indecorosa colocava em risco a segurança do bem comum ${ }^{13}$, daí o crime ser tipificado como sendo de lesa-majestade.

\footnotetext{
10 "de las cuales nadie es capaz de arrancar sentido alguno si no se conoce el abededario y el significado convencional de las palabras que usan entre sí" (FARIA E SOUSA, 1975, p. 872).

11 "Platicábase que en la secretaría de la embajada solía haber un oficial mayor que atendía solamente a los papeles que se escriben en cifra" (FARIA E SOUSA, 1975, p. 238).

12 RIVAS ALBALADEJO, 2015, p. 286.

13 "Si yo supiera entonces lo que después supe, aún pudiera decir más acerca de esto; y es que el marqués llegó a hacer de él una confianza que ningún fiel y prudente ministro puede ni debe hacer de su padre o de su hijo, y fue mostrarle la instrucción secreta que llevaba del rey para aquella embajada; crimen totalmente grande." (FARIA E SOUSA, 1975, p. 264).
} 


\section{Conclusằo}

De acordo com Francisco Moreno Porcel, autor do Retrato (1650), na Madrid da década de 1640 circulavam diversos murmúrios que acusavam Faria e Sousa de ingratidão. ${ }^{14} \mathrm{Em}$ resposta a esses falatórios, que possivelmente obstavam o seu trânsito na corte, o escritor compõe uma assim chamada limpeza de vida (FARIA E SOUSA, 1975, p. 342). No papel, o letrado expõe com minúcias de detalhes os acontecimentos transcorridos na embaixada de Roma, segundo o seu ponto de vista, na condição de um ex-funcionário de Castelo Rodrigo. Com efeito, no âmbito do forense, o discurso consistia numa defesa de procedimentos. Como um típico memorial de serviços (espécie da epistolografia em que o servidor apresenta sua excelente folha de trabalhos, em geral, ambicionando um propósito prático, como a obtenção de prêmios ou a promoção no cargo), Faria e Sousa narra em primeira pessoa as suas ocupações, para demonstração de sua conduta ética ilibada. Mas não só, também o papel amolda um discurso de ataque. Com virulência, o escritor levanta uma grave acusação contra Castelo Rodrigo, conectando-Ihe um sem-número de crimes contra o bem comum. Entre outras faltas, o letrado acusa Castelo Rodrigo de cometer crimes da fazenda, propor a falsificação de documentos, bem como revelar as instruções secretas de sua missão em Roma.

\section{Referências}

ASENSIO, E. Camões en la poesía española de los siglos XVI y XVII. Arquivos do Centro Cultural Português, Paris, XV (Separata), p. 111-132, 1980.

EXTREMERA EXTREMERA, M. A. El delito en el archivo. De escribanos, falseadores y otras gentes de mal vivir en la Castilla del Antiguo Régimen. Hispania, Madrid, LXV/2, n. 220, p. 465-484, 2005.

FARIA E SOUSA, M. d. The "Fortuna" of Manuel de Faria e Sousa: an autobiography. Münster Westfalen: Aschendorff, 1975. Introduction, edição, notas e index por Edward Glaser.

14 "Yo por ventura aurè excedido, mas tambien es alabança de MANUEL DE FARIA el bolver por su reputacion, calumniada iniquamente. Pero prosigamos sus Elogios." (MORENO PORCEL, 1650, $\S L X I X)$. 
GARCÍA CUETO, D. Mecenazgo y representación del Marqués de Castel Rodrigo durante su embajada en Roma. In: HERNANDO SÁNCHEZ, Carlos José (Org.). Roma y España: un crisol de la cultura europea en la Edad Moderna. Madrid: Seacex, 2007, p. 695-716. 2v.

MARAÑÓN, G. Olivares: a paixão de mandar. Lisboa: Aster, [19--].

MARTÍNEZ HERNÁNDEZ, S. Os marqueses de Castelo Rodrigo e a Nobreza portuguesa na monarquia hispânica: estratégias de legitimação, redes familiares e interesses políticos entre a agregação e a restauração (1581-1651). Ler História, Lisboa, n. 57, p. 7-32, 2009.

MARTÍNEZ HERNÁNDEZ, S. Aristocracia y anti-olivarismo: el proceso al marqués de Castelo Rodrigo, embajador en Roma, por sodomía y traición (1634-1635). In: MILLÁN, José Martínez; RODRíGUEZ, Manuel Rivero; VERSTEEGEN, Gijs. La Corte en Europa: política y religión (Siglos XVI-XVIII). Madrid: Ediciones Polifemo, 2012. p. 1147-1196. V.III.

MONTAIGNE, M. d. Ensaios. Trad. e notas de Sérgio Milliet. São Paulo: Editora 34, 2016.

NISHIHATA, M. M. Estudo retórico-poético sobre La Fortuna, de Manuel de Faria e Sousa. 2021. 234 f. Tese (Doutorado em Letras) Faculdade de Filosofia, Letras e Ciências Humanas, Universidade de São Paulo, São Paulo.

QUIÑONES, I. d. Tratado de falsedades. Delitos que cometio Miguel de Molina, i suplicio que se hizo del en esta Corte (...). Madrid: en La Imprenta de Francisco Martinez, 1642.

RIVAS ALBALADEJO, Á. Entre Madrid, Roma y Nápoles. El VI conde de Monterrey y el gobierno de la Monarquía Hispánica: (1621-1653). 2015. 991 f. Tese (Doutorado em História) Facultat de Geografia I Història, Departament D'Història Moderna, Universitat de Barcelona, Barcelona.

SENA, J. d. Introdução. In: CAMÕES, Luís de; FARIA E SOUSA, Manuel de. Lusiadas de Luis de Camões: comentadas por Manuel de Faria e Sousa. Lisboa: Imprensa Nacional - Casa da Moeda, 1972. p. 9-56. Ed. facsimile de: En Madrid: por Ivan Sanchez, 1639. 